\title{
Gender differences in youth attitudes towards suicide prevention during a community-based theater program
}

\author{
Joy C. Honea ${ }^{1, *}$, Sarah N. Keller ${ }^{2, \dagger}$, Vanessa McNeill ${ }^{2, \dagger}$ \\ ${ }^{1}$ Department of Social Sciences and Cultural Studies, Montana State University Billings, Billings, MT 59101, USA \\ ${ }^{2}$ Department of Communication, Montana State University Billings, Billings, MT 59101, USA \\ *Correspondence: jhonea@msubillings.edu (Joy C. Honea) \\ ${ }^{\dagger}$ These authors contributed equally. \\ Submitted: 31 August 2021 Accepted: 8 October 2021 Published: 19 January 2022
}

\begin{abstract}
Background: To explore the differences in young adult male and female attitudes towards and motivations for suicide, beliefs about help-seeking behavior, and attitudes towards helping others to prevent suicide. Methods: In-depth interviews and focus groups with adolescent and young adult males and females $(n=50$, ages $14-24)$ were conducted before and after a community-based play on suicide prevention. Two focus groups and 30 individual interviews ( $n=50,22$ males, 28 females) were conducted before the intervention at one location, and 12 in-depth interviews (4 males, 8 females) were conducted with some of the same individuals after the play. The transcripts were coded by two independent coders for gender differences. Emergent categories were analyzed to identify differences in responses to issues surrounding suicide and depression. Results: Three key gender differences were found in communication styles around emotional vulnerabilities: (1) Females were more likely to talk about the importance of reaching out to others and giving counsel, while males were more likely to expect others in need to seek them out for help. (2) Females talked about psychological distress as something "everyone" experiences, while males tended to see their suffering as an individual phenomenon. (3) Females tended to advocate disclosure while males talked about the pressure not to talk about personal problems. Conclusions: Young males and females may need different coping strategies, and interventions, therefore, must be tailored to address the needs of each gender separately. Campaigns and programs specifically for men should address the barriers that men face with disclosure and help-seeking, and strategies should be sensitive to the expectations of heteronormative masculinity.
\end{abstract}

Keywords: Gender differences; Suicide; Help-seeking behavior; Suicide prevention

\section{Introduction}

The male suicide rate in the United States is nearly triple the death rate from suicide for females (CDC), and in other countries the disparity is similar, although slightly less drastic [1,2]. While men die more often from suicide attempts, women make roughly three times the suicide attempts, and show higher rates of suicidal thinking, non-fatal suicide behavior, and depression [3]. This is commonly called the "gender paradox" in suicidality. Possible explanations for these differences include the fact that men use more lethal means when they do attempt suicide, such as firearms; higher rates of substance abuse among men; higher rates of help-seeking behavior among women; and differences in psychological contributors to suicide found among genders [4]. In addition, the evidence suggests that psychosocial factors like unemployment, retirement and being single are linked to increased suicide risk for men, but not for women [5-7].

This suggests that gendered expectations of behavior play a role in suicidality. While women may experience higher levels of psychological distress, this does not translate into more suicide. And if non-lethal suicide attempts are considered help-seeking behavior, this indicates that women are more likely than men to seek help for mental distress. Since help-seeking is stigmatized as a feature of heteronormative masculinity, men may be less willing to engage in this behavior. Research with male college students confirms this conjecture. In a study on barriers to help-seeking through professional counseling, Lloyd et al. [8] found that "Participants" discourses constructed gender roles as being a large barrier to seeking help, especially for males. Men were perceived as having to be "strong" and cope on their own, with any admission of feelings or need for support as compromising their male roles, suggesting that help-seeking for males undermines their masculine identity. Indeed, men report higher rates of stigma about mental illness, help-seeking, suicide and disclosure of emotional vulnerability compared to women [8].

Stigma surrounding mental illness and suicidality, in particular, has been documented as an immediate and profound barrier to help-seeking behavior [9]. Stigma can take emotional, cognitive, or behavioral forms, and it can be directed at oneself or others. Stigma is sometimes defined as a collective phenomenon, echoing societal views on mental illness. Research has shown that mental illness stigma reduces patients' perceived need for help [10], impairs adherence to treatment regimens [11], decreases self-esteem [12], and increases social isolation [13]. Self-stigma, a variation 
of collective stigma, is a process in which a person with a mental illness internalizes stigmatizing attitudes and beliefs held by the public [14]. Based on comparative studies across countries, Schomerus et al. [10] posit that national variations in suicide rates may actually reflect variations in cultural beliefs about mental illness and stigma.

Scholars have identified three primary mechanisms to explain how stigma contributes to suicide. First, according to the stress-coping model of stigma [10], stigma is seen as a social stressor that promotes "negative emotional reactions, social withdrawal, and hopelessness among people with mental illness, especially if the perceived threat of stigma and social rejection exceeds the coping resources of the individual" (pp. 4). Second, stigma contributes to the social isolation of a person experiencing a mental health problem, in part by discouraging interaction and a sense of belonging with others. Social isolation, in turn, is believed to contribute to the risk of suicide, in part, by reducing the desire to discuss one's mental health status with others [10]. Third, community-wide stigma is associated with individual self-stigma [14]. "Studies on predictors of help-seeking have shown that both individual stigmatizing attitudes and self-stigma are associated with lower willingness to seek help for mental health problems, which could, in turn, increase the individual risk for suicide" [10] (pp. 4).

Recognizing the role of stigma in preventing helpseeking, particularly among men, numerous organizations and public health agencies around the world have developed suicide prevention programs aimed specifically at men. Many of them are directed at men with particular lifestyles or occupations. For example, in the U.S., the Shoulderto-Shoulder program focused on U.S. military personnel from 2010-2018. The Army's campaign “challenged dominant discourses of military masculinity, privileging familial and homosocial responsibility over stoicism, toughness, and self-reliance and casting suicide as a failure to be appropriately masculine" [15] (pp. 306). The message was that it's part of one's manly duty to continue living and to help others. As such, the campaign attempted to harness conventional understandings of masculinity to reframe seeking help for psychological distress as "being a real man". While the campaign was cheered for its efforts to define helpseeking as part of accepted masculinity, its effects have been limited and the Army's suicide rate remains high [15].

Other examples include the "Good Hunting, Mate" campaign in Finland, aimed at men who were members of hunting clubs, and the "Time Out!" program, also in Finland, for men who were exempted from that country's military or civil service requirement [16]. In Australia and New Zealand, the "Mates in Construction" program is an industry-led initiative to provide peer support and workplace-based resources for suicide prevention outside of a clinical setting [17]. These programs generally focus on barriers to help-seeking and psychological health that are particular to those sectors and the men who live and work in them, but many of them do acknowledge the stigma surrounding needing help and asking for it that is common among men overall.

Some campaigns aimed at men are less specific in their focus and have been developed to encourage specific types of behavior among the target audience. The global "Movember" organization is dedicated to improving men's health generally but it includes suicide prevention efforts. The "be a man of more words" slogan tells men that "Stronger social connections can reduce the risk of suicide. That means more men talking about stuff that really matters. Those conversations don't always come easy, but we're here to help" [18] (https://us.movember.com/menshealth/suicide-prevention). The organization also funds smaller projects like Australia's "Man-up" campaign, a three-part video series designed to raise awareness about male suicide in that country. Its website states, "Harden up. Suck it up. Man up. We've been telling our men this for years, but is it healthy? Suicide is now the leading cause of death for Australian men aged 15-44. And alarming new research suggests that some men choose to take their own life, rather than appear weak by asking for help" [18] (https://au.movember.com/mens-health/manup). What these efforts all hold in common is an acknowledgment of the pressure men face to conform to ideals of normative masculinity and the stigma associated with both suffering from emotional distress and asking for help to cope.

Given the significantly higher suicide rate of men globally, norms of masculinity and the role of stigma in preventing help seeking, it is imperative that suicide prevention researchers and practitioners continue to develop and refine gender-specific public health messaging and interventions. In their review of existing suicide prevention programs, Hamilton et al. [19] found that females are almost always more likely to benefit from existing programs than males. They recommend implementing strategies to address key barriers to help-seeking for mental health problems among men, such teaching young men to build networks of support, preferably before help is needed [20]. Gulliver et al. [21] recommend appealing to young people's need for self-reliance, reducing stigma, and improving mental health literacy. This study aimed to contribute to the literature by exploring self-reported experiences of psychological distress and responses to mental health challenges among adolescent and young adult male and female participants in a community-based theater program focusing on suicide prevention. The results hold the potential to better inform campaigns focused on increasing help-seeking among men and to aid in the development of prevention campaigns for pre-teen and adolescent boys, in particular. 


\section{Material and methods}

\subsection{The project}

This study was conducted as part of a larger suicide prevention program that used community-based theater productions to encourage actors and audiences to talk more openly about psychological distress, mental health concerns and suicide. The project, called "Let's Talk", involed a series of five theater programs in two communities between 2012 and 2015. The focus was on the prevention of suicide among teens and young adults so recruitment occurred at high schools and a university campus. Participants wrote and acted in the plays but professional directors guided the script writing and rehearsals to ensure that three themes were included: (1) interpersonal communication about suicide risk is important, (2) professional resources for suicide prevention exist and can be helpful, and (3) talking about suicide risk and resources can reduce barriers to prevention. The format and content of the plays varied based on the participants' preferences but all were approximately 20 minutes long and were followed by 40 minutes question and answer sessions led by professional counselors.

Over the course of three years, the Let's Talk research team hosted and facilitated theater workshops that led up to each play, with five different groups of students who met bi-weekly for 12 weeks to share their personal experiences with suicide and/or major depression, and to collaboratively write a unique script based on their experiences. At the end of the writing-rehearsal period, the writer-actors staged performances for their peers and communities, after which they held discussions with audience members. Each discussion was moderated by a psychiatrist or a volunteer trained to help answer difficult questions and elaborate on the discussions that unfolded during the Q\&A. The performances and subsequent discussions were intended to teach other students and community members how to talk to their peers and mental health professionals about suicidal ideation, loss, and prevention.

\subsubsection{Recruiting, writing and rehearsal}

At each participating high school and university, subjects were recruited via classroom announcements and word-of-mouth, asking volunteers to take part in writing and performing an original play about suicide and depression. Student status and interest in the program were the only screening criteria used to select these participants. They did not undergo mental health screening, but voluntary reports of mental illness or history with counseling were noted. Subjects were informed of their right to withdraw from the study, and were given a consent form to read and sign before starting the 10 -week rehearsal and production process. For the first meeting, an outside specialist administered QPR (question, persuade, refer) suicide prevention gatekeeper training, which provided the initial platform to talk about such a personal and painful topic. For partici- pants under age 21, parental consent was obtained.

At the initial workshop rehearsal, a director (manager of a community theater and a university theater professor) gently probed the writer-actors' experiences with stress, anxiety, depression, alienation from school and home, and relationships. As suggested by the Narrative Engagement Framework [22], students were encouraged to share their personal narratives, in order to develop messages that would be meaningful to other adolescents or young adults. During the writing/rehearsal period, discussions and improvisational exercises guided by the director addressed students' desire to be impervious to bullying, the myriad challenges faced by individuals coming from rural backgrounds, and the challenges of attending large schools. The feeling of having a "misfit" identity, coupled with the desire to fit in, was a common theme. Overwhelming feelings of being alone, and a sense of engaging in perpetual competition with their peers, were salient throughout the discussions at both the college and high school levels.

Throughout the playwriting process, workshop members shared journal entries, stories, memories, songs, and poetry with the director and the rest of the group. By contributing creative non-fiction based on their own experiences with self-harm (e.g., cutting), suicidal ideation, suicide attempts, and grief over a friend's or family member's suicide, the writer-actors collaboratively created an original narrative theatrical performance $[22,23]$.

\subsubsection{Performance and discussion}

At the end of the rehearsal period, ten performances by five writer-actors were staged at the university level; three performances by fifteen writer-actors were staged by high school students. Performance venues varied from university settings to community theaters to regional high schools, and audiences were recruited through classroom announcements and community-wide publicity. Before each performance, audience members were given reference cards containing crisis prevention hot-line numbers and local mental health resources. A member of the research team introduced each performance with a brief explanation of the Let's Talk program, the importance of the research, and the need to eradicate stigma surrounding mental illness and suicide. Each performance lasted 20 minutes, followed by a moderated 40-minute Q\&A session.

In addition to dramatizing the distress that mentally ill and suicidal people experience, each performance was designed to model: (1) adaptive decision-making strategies in times of stress, (2) accessing emergency help, (3) providing ongoing support to peers during a crisis, and (4) identifying at least one caring adult in the school or community from whom to seek help [24]. Following this structure, in their opening scenes, the performances demonstrated the destructive power of negative self-talk.

In addition to negative self-talk and stigma, the scripts covered barriers to help-seeking, and messages of hope. At 
the end of the play, the director introduced the writer-actors and mental health professionals who would moderate the discussion, and initiated the Q\&A session. The performers sat on the edge of the stage facing the audience. The first question, posed by the director or an actor, was always: "How many in here have had some experience with suicide?" Most audience members and actors would raise a hand. Following this opening, each Q\&A was different, based on the audience. Sometimes, audience members would spontaneously start sharing their own experiences with loss and asking questions of either to the moderator or the performers. Other audiences were more reticent, in which case, the moderators would try to initiate a conversation by discussing barriers to help-seeking and highlighting available resources.

With more reserved audiences, the moderators would pose open-ended questions, encouraging audience members to share their concerns and discuss barriers to helpseeking and open dialogue about suicide and suicidal ideation. Inevitably, audience members would talk about their experiences. In all situations, the performers would participate in the Q\&A, talking about their experiences with surviving suicide, counseling, trials and errors involved in finding the right mental health professional, and sharing their individual experiences of stigma within their communities, schools, and homes.

\subsection{Data collection}

In order to gain insight into participants' views on the experience of psychological distress/suicidal ideation, beliefs about strategies to improve mental health and perceived barriers to help-seeking, members of the theater project and audiences were recruited for IRB-approved indepth interviews and focus groups. The interview were conducted with adolescent boys and girls and young adults (ages 14-24) before and after one community-based suicide prevention intervention. The Montana State University Billings Institutional Review Board (IRB00001622) approved this study. All participants signed informed consent forms; none refused participation. Each interview lasted about 2 hours. Interviews and focus groups before the intervention involved 50 consenting participants, both actors in the play and audience members who attended the high school. Two separate focus groups (one small group, $n=4$ and one with an entire high school class, $n=16$ ) were conducted, plus 30 individual interviews (boys: $n=22$ and girls: $\mathrm{n}=28$ ). In addition, 12 individual interviews of actors in the play were conducted after the performance (boys: $n=$ 4, girls: $n=8$ ). While age homogeneity is recommended in studies such as this one, the high number of non-traditional students at the university produced a broad range within our subjects - from 14 to 24 years old. Sixty-six percent of participants were female. Interview group sizes ranged from four to 16 people, and groups were divided by type of involvement, either audience members or writer-actors.
During these sessions, the research team collected personal narratives, field notes, and visual images [25]. All interviews were moderated by a university researcher trained in qualitative research methods, and were video-recorded. Following a semi-structured approach [26], interviews explored participants' attitudes and knowledge about suicide and help-seeking, as well as their past experiences (positive and negative) with suicide and mental health counseling. All group interviews were recorded, transcribed verbatim, and compared with the original recordings to ensure transcription accuracy.

Constructs from the Extended Paralell Process Model (EPPM) were used to elicit information about participants' perceived threat of suicide and perceived efficacy for accessing help or helping others. The EPPM examines the role of perceived threat and perceived efficacy in relation to health behaviors [27]. In the post-test round of interviews, after writing/performing or viewing the play (depending on the group), participants answered questions regarding self-identified changes in their perceptions of the EPPM constructs discussed during the first interviews. Because EPPM emphasizes people's perceptions of threat and efficacy (rather than objective measures of threat and efficacy), post-interview questions focused on participants' perceptions of how the Let's Talk project had helped them (or not). For example, a typical post-intervention question was, "I'm wondering if, after being part of the play, you feel like you know more about how to get help for yourself or a friend who was feeling depressed or suicidal?" Other questions were written to help explore, pre-intervention; "How comfortable are you with talking about suicide? Is it something that you and your friends talk about or not?" "If you were having negative or suicidal thoughts, is there someone you would talk to? A counselor or a parent or a friend?" And then post-intervention, the question would be "Would you be more likely to talk to someone about your problems now that you've seen the play" and then prompts would depend on the responses to the initial questions so they included questions like "What would make you more likely to tell a friend to talk about their problems?" or "Why might you or your friends still be reluctant to go talk to an adult about your problems or negative thoughts?". The emphasis in all questions was on the subjects' perceptions, based on their experiences and beliefs, rather than on any behavioral changes made in the time between the first and second interviews.

Following completion of the group discussion, participants were thanked and entered into a lottery to receive an iPad Mini (\$250 value) as compensation for their participation. All videotapes were transcribed verbatim and carefully compared with the original recordings to ensure transcription accuracy. Personal identifiers were removed and the transcripts were distributed to four coders. The larger research aim of the project was to evaluate the effectiveness of the theater interventions, using the EPPM to identify 
Table 1. Main coding categories, sub-categories and descriptive themes.

\begin{tabular}{|c|c|c|c|}
\hline Supra codes & Main codes (1st Layer) & Sub-categories (2nd Layer) & Descriptive themes (3rd Layer) \\
\hline & Barriers to Help-Seeking* & & Symptomatic behavior: \\
\hline & *(derived from EPPM constructs of Low Perceived Self-Efficacy and & & truancy \\
\hline & Low Perceived Response Efficacy) & & \\
\hline & & & $\begin{array}{l}\text { Symptomatic behavior: } \\
\text { substance abuse }\end{array}$ \\
\hline & & Defense Avoidance & Maladaptive coping strategies \\
\hline & & & (e.g., not considering help) \\
\hline & & & Reactance \\
\hline & & & (blaming the messenger) \\
\hline & & & Defensiveness \\
\hline & & & Denial \\
\hline & & Lack of Resources (geographical distance) & \\
\hline & & Cost & \\
\hline & & Stigma Against Treatment & \\
\hline & & Negative Perception of Treatment Efficacy & \\
\hline & & Lack of Awareness (of how to find help) & \\
\hline & & Fear of Being Shunned & \\
\hline & & Experience of Being Shunned & \\
\hline & & Lack of Problem Recognition & \\
\hline & & Lack of Access (to sources of support) & \\
\hline & & Vulnerability & \\
\hline Individual vs. & & Stigma (about mental illness) & \\
\hline \multirow{22}{*}{ communal orientation } & Factors of Suicide* & Social Isolation (Loneliness) & Feelings of loneliness/Isolation \\
\hline & *(derived from EPPM construct of Perceived Severity) & & Disconnection from others \\
\hline & & Perceived Burdensomeness & $\begin{array}{l}\text { Thwarted belongingness } \\
\text { (Stable, unchanging v. Transient) }\end{array}$ \\
\hline & & Negative family dynamics & \\
\hline & & Suicidal ideation & Self-hatred \\
\hline & Survivor Responses & Confusion/Perplexed & \\
\hline & & Anger & Perceive oneself as a burden \\
\hline & & Guilt & Belief that one's death would be worth more than one's life \\
\hline & Behavioral Intentions* & To Communicate with Others about Suicide/Depression & Sharing emotional vulnerability \\
\hline & *(derived from EPPM constructs of Self-Efficacy \& Response Efficacy) & To Engage with Prevention Resources & Coping strategies \\
\hline & & To Access Help & \\
\hline & Stigma* & What is being Stigmatized & Emotional Vulnerability \\
\hline & Self-Reports of Mental Health Issues & Experience with Stigma & Needing Help \\
\hline & *(derived from EPPM construct of Perceived Susceptibility) & & Mental Health Treatment \\
\hline & & & Mental Illness \\
\hline & & Hopelessness & Towards Mental Illness \\
\hline & & Self-harming & Towards Mental Health Treatment \\
\hline & & Isolation (loneliness) & Against Needing Help \\
\hline & & Uncontrollable Thoughts & Sharing Emotional Vulnerability \\
\hline & & Helplessness & \\
\hline & & Depression & Confusion \\
\hline & & Suicidal ideation & \\
\hline
\end{tabular}


changes in perceived threat and perceived efficacy of helpseeking. But during the analysis phase, gender specific themes emerged from the transcripts and thus the project was expanded to explore those differences.

\subsection{Research questions}

(1) What attitudes do participants express related to helping others who are experiencing psychological distress and do these attitudes differ by gender?

(2) What experiences do participants have with their own mental health problems and/or psychological distress among their friends and family and are there gender differences in how they talk about these experiences?

(3) How do participants feel about disclosing personal experiences of psychological distress and what is their sense of community attitudes surrounding personal disclosure? Do their responses vary by gender?

\subsection{Data analysis}

In the analysis of gender differences in the data, the researchers returned to the original codes and looked for patterns in responses among the male and female participants. Gender-related themes were independently coded by two of the researchers and then compared for reliability. A third coder reviewed the coded transcripts and reconciled any discrepancies in the original coding process. All three researchers then collaborated to match the original EPPM codes to the gender-specific research questions developed for this phase of the study. Results were compared to literature on gender differences in communication styles around emotional vulnerabilities. All personally identifying information was stripped from the data, and pseudonyms were assigned to participant responses.

Code development: To analyze the data, three members of the research team (one professor and two graduate assistants trained in qualitative research) read the transcribed interviews independently several times, looking for primary themes related to the a priori categories, as well as emergent ideas. The team's analytical approach was informed by coding methods laid out by Miles and Huberman [26], Corbin and Strauss [28], Fairclough [29], and DeCuirGunby, Marshall, and McCulloch [30]. The team began developing codes by listing general categories of conceptual variables (e.g., barriers to help-seeking; self-efficacy for disclosure; self-efficacy for helping others; behavioral intentions; perceived response-efficacy of disclosure; perceived response-efficacy for helping others; perceived susceptibility to depression/suicide; perceived severity of depression/suicide; etc.). These a priori categories were constructed during an earlier study that analyzed information collected during focus groups comprised of writer-actors and audience members [23]. The coding team clarified the operational definitions of these categories and collectively reviewed several examples of each to ensure uniform interpretation of the definitions. The complete list of a priori categories is included in Appendix Table 7.

After achieving consensus on the main categories through the process described below, the team began opencoding a subset of the transcripts [26], using both the a priori categories, and identifying additional ideas as they emerged. As needed, the team refined the categories, renaming codes as needed [29] and using axial coding [28], to identify how passages in the data might be arranged into main- and sub-codes (Table 1). As the team worked through the coding process, they noted that the voices in the transcripts varied substantially in whether they identified problems and solutions as individual or communal in orientation. As such, the team created a supra-code across all categories, so that they could classify voices as being communally or individually oriented. This iterative cycle continued through several meetings until the team was satisfied that they achieved consensus coding definitions they could apply the main, sub-, and supra-categories in the remaining transcripts.

This team first practiced coding by using sub-samples of the video footage to become familiar with the variables and to resolve emergent questions. Once the codebook was established, the coders worked independently to assign codes to the complete transcripts from all five recorded performances (minus what they used to establish the codes). Codable passages included any scenes or statements in the transcripts that fit into one or more of the main categories, according to the coders $(\mathrm{n}=452)$. Each coder identified the main categor(ies) and sub-categor(ies) that best fit each passage.

Reliability was assessed by measuring the agreement between each of the independent coders. Based on Wimmer and Dominick's [31] recommendation of using a sample of between $10 \%$ and $25 \%$ of the study Textual in order to perform reliability testing, coder and intercoder agreement was measured using Hayes and Krippendorff [32] to compute Krippendorff's alpha $(\alpha)$ reliability estimate for judgments. Initial reliability scores were low, leading to in-depth discussions among the entire research team, referencing the codebook when necessary, to discuss themes and their interrelationships [33]. After these discussions, and re-coding the transcripts from scratch, the research team calculated interrater reliability at $83 \%$ (Table 2). All discrepancies in the coding were highlighted for further discussion. Next, the entire qualitative team analyzed the interview transcripts and initial results, using axial and selective coding to identify larger categories and concepts and their interrelationships [28]. Finally, the senior members of the research team identified places in the coding that aligned with EPPM, and came to agreement on the larger conceptual pictures that emerged.

From this exhaustive system, the coders then reached agreement on the themes pertaining to conceptual constructs found within the EPPM; specifically, those relating to perceived susceptibility to suicide, perceived sever- 
Table 2. Percentage agreement between coders and percentage of passages in which coding categories appeared (See Appendix Table 7 for all coding categories).

\begin{tabular}{|c|c|c|c|c|}
\hline \multirow{2}{*}{\multicolumn{2}{|c|}{ Category }} & \multirow{2}{*}{ Percent agreement } & \multicolumn{2}{|c|}{ Frequency in transcripts } \\
\hline & & & \multicolumn{2}{|c|}{ N (\%) } \\
\hline \multicolumn{2}{|c|}{ Individual vs. communal orientation } & 88 & \multicolumn{2}{|c|}{$52(12)$} \\
\hline \multicolumn{2}{|c|}{ Self-reports of mental health } & 83.1 & \multicolumn{2}{|c|}{$153(34)$} \\
\hline \multirow{4}{*}{ Stigma } & Public Stigma & 82.1 & $23(5)$ & \multirow{4}{*}{$94(21)$} \\
\hline & Self-Stigma & 80.2 & $15(3)$ & \\
\hline & Stigma of Help-Seeking & 88 & $23(5)$ & \\
\hline & Thwarted Belongingness & 88 & $31(7)$ & \\
\hline \multirow{3}{*}{ Behavioral intentions } & Helping Others & \multirow{3}{*}{86} & \multirow{3}{*}{$66(15)$} & \\
\hline & Seeking Help & & & \\
\hline & Talking & & & \\
\hline Copking skills & $\begin{array}{l}\text { Self-Expression } \\
\text { Activities, Escape }\end{array}$ & 84 & $22(5)$ & \\
\hline
\end{tabular}

ity of suicide, perceived self-efficacy regarding counseling, and perceived counseling efficacy (response efficacy). The coders then returned to the data to assess independently the adequacy of the categorical system, including the set pertaining to the EPPM, after which they reconvened to discuss their conclusions and triangulate their perspectives. After reconciling minor discrepancies, the coders returned to the data one last time to test the exhaustiveness of their categorical system. Through this process, the team codified an inventory of suicide knowledge raised by participants that pertain to the EPPM.

\subsection{Limitations of the sample}

Because participants were recruited from a youth theater project for suicide prevention, they had prior suicide prevention training on the importance of disclosure about suicidal thoughts and fears so they likely were not representative of the larger community of adolescents. However, because there had been several recent youth suicides in the community, virtually all students in the high school had prior exposure to discussions about suicidality and suicide prevention.

There were also fewer males in the sample than females, since the participants self-selected to be involved in the theater production. It was also a relatively non-typical sample of young adult males. Male participants tended to be more open to disclosure and helping others than typical, according to the literature. This is likely a a feature of the characteristics of adolescent boys who chose to be involved. In terms of the racial make-up of the participants, half of male participants were Native American. The community in which the study was conducted has a significant Native American population and because suicide is an even larger problem among Native Americans than the general population, the researchers were not surprised that a large number of theater volunteers identified as American Indian.

There are cultural differences among Native populations that indicate a more communal attitude towards help- seeking/helping others than in the white population. Both ethnic groups report that stigma is a barrier to expressing emotional vulnerability, seeking help, and acknowledging mental illness. However, Keller et al. [34] found that Caucasians' experiences are more individually oriented and $\mathrm{Na}$ tive Americans' experiences are more collectively oriented. Understanding the cultural bases of experiences of stigma related to mental health treatment for suicide is necessary to create educational programs to reduce stigma for diverse groups of adolescents and young adults.

Based on comparative studies across countries, Schomerus et al. [10] posit that national variations in suicide rates may reflect variations in cultural beliefs about mental illness and stigma. Furthermore, suicide rates vary by region within national borders, and within ethnic enclaves within regions, reflecting different stressors, levels of stigma, and how normative suicide seems as a cause of death among community members. Many countries report increased, yet varied, risks of suicidal behaviors among adolescents in immigrant communities [10]. Identified stressors include ruptured family structures, difficulties acculturating to a host country's cultural and religious traditions, language barriers, and particularly socioeconomic status, which can become a potentially lethal combination [35-38]. In Montana and elsewhere, Native Americans (NA) have a unique situation in that they experience all these difficulties, yet they live in their country of origin, i.e., they are guests in their own country. Lalonde, discussing Indigenous First Nations Canadians, describes this as "...the special circumstance of finding oneself tugged by both enculturative and acculturative currents" [39] (pp. 139). At present, many NA communities in Montana lack sufficient social, emotional, and financial resources, which may increase suicidal behavior risks [40,41]. Nationwide, Indigenous youth are 2.5 times more likely to experience suicidal ideation or attempts than youth from other racial/ethnic youth groups [42]. 
Table 3. Attitudes towards helping and coping by gender*.

\begin{tabular}{lccc}
\hline Helping others and coping skills & Frequency in category N (\%) Frequency for females N (\%, sub-category) & Frequency for males N (\%) \\
\hline Engage with prevention resources & $23(26)$ & $16(18)$ & $7(8)$ \\
Talk to others & $6(10)$ & $6(10)$ & - \\
Self-expression & $12(14)$ & $11(13)$ & $14(1)$ \\
Escape, activities & $16(18)$ & $2(2)$ & $5(6)$ \\
Reaching out to others & $23(16)$ & - & $8(9)$ \\
Expecting others to contact you & $8(9)$ & & \\
Total & $88(100)$ & $(20)$ & \\
\hline *The categories of Behavior Intentions $(\mathrm{n}=66,15 \%$ of transcript) and Survivor Responses $(\mathrm{n}=22,5 \%$ of transcript) combined to generate this table.
\end{tabular}

The characteristics of the participants in the sample meant that the individuals who were interviewed, especially the boys, were probably less invested in traditional EuroAmerican gender roles and heteronormative masculininity than the larger population. But even in our non-typical sample, there were some substantial stereotypically gendered results.

Finally, the fact that recruitment occurred as part of a community theater project, the risk of social desireability bias was high. Participants (actors or audience members) may have been likely to give the answers they expected the researchers wanted to hear, rather than their authentic comments. Since the theater project was educational in nature, with a focus on prevention, it is especially likely that interviews conducted after the play would provide exaggerated opinions about the potential benefits of the play and open disclosure in helping others.

\section{Results}

\subsection{Attitudes toward helping others}

Coded themes related to perceived self-efficacy largely revolved around interview subjects' increased willingness to talk about suicide, increased self-confidence to help others, and increased willingness to contact professional help. After the workshops and multiple performances, the writer-actors indicated levels of empowerment and perceived self-efficacy that transcended our expectations. Girls were more likely to talk about the importance of reaching out to others and the specifics of how to listen and how to give counsel (Table 3). One student said proudly:

We are going to use that growth and those skills every day of our lives, even when we are talking to little children. We are going to learn how to bring it down to their level so they understand... I think every day we are going to use a skill we used from this play (Melissa, 18).

Particularly strong was an articulation of increased self-efficacy to help others who may be struggling with mental health problems: "Yeah of course, I'll always come back to this [play] because it's something that I am so proud of because we helped so many people," said Melissa.

Female audience members expressed significant changes from baseline to post-intervention regarding their attitudes towards the effectiveness of helping others and accessing professional help. One audience member, aged 19, who experienced a suicide attempt by a co-worker shortly after seeing the performance, suggested that more suicide prevention theater performances would be helpful throughout the community. She also expressed increased selfconfidence in the effectiveness of listening to friends who are in trouble:

You know, not like "act" like I care you know, but more of a "be present" with who you're face-to-face with, you know? It really did shed light on so many people that struggle with these kinds of issues.

Boys, on the other hand, were more likely to expect others in need to seek them out for help and talked about helping others in more formal and less personal terms (i.e., "it's important for the community to help with social change").

Male participants perceived an increased sense of selfefficacy after their involvement with the project, but they envisioned themselves as recognized community leaders, rather than simply being able to respond to friends in need. In response to a question about how the Let's Talk program made him feel, Jarred, 16, replied: "Oh, powerful. No adult has ever asked for my help. Anyway, I just felt powerful. I just had the knowledge to help people. Words are powerful - they can hurt or help".

Another student described his feeling of empowerment from being able to lead a suicide prevention effort. Kevin, 17, said: "This project with the message we're trying to convey here - probably the most rewarding piece I've ever been involved with and to know that we're putting something out there that's really breaking down walls to me - that's what I would say. And it's the best feeling in the world. I don't want to say this topic is good; but it's good the walls are coming down".

In terms of expecting others to come to them, one high school audience member said:

I think before we'd all want to be a good friend to (a suicidal friend or family member), so we'd hope they'd come to us, but definitely after this project there's way more incentive and we're definitely more prepared for that (Brian, 17). 
Table 4. Beliefs about individual vs. communal suffering.

\begin{tabular}{|c|c|c|}
\hline & Males & Females \\
\hline \multirow[t]{4}{*}{$\begin{array}{l}\text { In response to the question, "What } \\
\text { do you think depression and suicidal } \\
\text { thoughts are something that many } \\
\text { people experience and can relate to, } \\
\text { or just a few?" }\end{array}$} & $\begin{array}{l}\text { "Nobody cares about me, not a } \\
\text { damn person. My teachers all hate } \\
\text { me because I'm not good enough for } \\
\text { them and, and, and..." }\end{array}$ & $\begin{array}{l}\text { "We had way too many [audience members] who knew some- } \\
\text { one who had dealt with suicide or had committed suicide, but } \\
\text { also a lot of people who probably had never met somebody or } \\
\text { spoken to them about having depression, anxiety, or any type } \\
\text { of mental illness." }\end{array}$ \\
\hline & $\begin{array}{l}\text { "No one listens to me. I'm com- } \\
\text { pletely alone." }\end{array}$ & $\begin{array}{l}\text { "But the fact is, it's so common. I know I have different family } \\
\text { members who have dealt with depression and severe anxiety } \\
\text { and stuff. And, like, there is a lot of stuff going on with them." }\end{array}$ \\
\hline & $\begin{array}{l}\text { "Why do I think of death when I } \\
\text { should think of life?" }\end{array}$ & $\begin{array}{l}\text { "...it just helps put everything together for more application. } \\
\text { And you know also to help understand just how many people } \\
\text { deal with it. So you don't feel like such a freak or get lost...." }\end{array}$ \\
\hline & $\begin{array}{l}\text { "Soon they won't have to deal with } \\
\text { their nothing of a son." } \\
\text { "I'm now completely alone." }\end{array}$ & \\
\hline
\end{tabular}

Despite the positive outcome the program had overall, male students' responses were not overly optimistic. While the play increased participants' awareness of the value of listening and talking to their peers, for at least one participant, it simultaneously increased his appreciation of the limitations on his ability to save people. Discussing a hypothetical situation that could end badly, Matthew, age 16, expressed a remarkably mature, nuanced combination of ambivalence and fear:

Well, I would want them to come to me (but) I kinda don't want them to come to me.... I'll talk them through it but my words didn't really help them and they end up killing themselves, so it's a burden on me, like, "Ahh I didn't end up helping them!" I'd be sad. I don't wanna have that burden but also I wanna help them. It's like Russian roulette.

When the teens were asked if they'd like a friend or someone they know to come to them if they were having suicidal thoughts, the females said yes they would like them to because they know how to help them and Let's Talk has given them those tools. Another male student, age 16, had similar answers followed by a concern: "But I would feel bad if I tried to help up them and they ended up killing themselves anyway. You only have a 50/50 chance of saving them". It was a tone of fear of losing them and fear of carrying that guilt if they couldn't save the friend.In sum, girls/young women were about twice as likely as boys to say that they would approach a friend to encourage them to seek help or help them get help themselves. While the girls saw helping others as a personal responsibility when a friend or other loved one seems to be struggling, boys took a more passive or impersonal approach (Table 4). Though, in general, they indicated that they would be willing to help a friend if asked, they didn't talk about taking the initiative to ask a friend or family member if they needed help. In addition, boys were more likely than girls to talk in impersonal terms about "people stepping up", rather than their own individual actions that could help.

\subsection{Experiences with depression or suicidal thoughts}

The girls interviewed talked about psychological distress as something "everyone" experiences. They were more likely than the boys to assert that feelings of depression are common in the community; something that the majority of people experience at one time or another even if they don't share that information with others (Table 4).

Female audience members' almost unanimously agreed that seeing the performance had increased their perceived severity of the threat around them.

Abby, 24, affirmed that watching the play had increased her ability to acknowledge the scope of the threat, stating: "There are really no true signs. Someone I said hi to yesterday, could easily go home and do something. You know, I mean that's... it's crazy to think that is just a split second choice". Rebecca apparently agreed with this conclusion, saying: "I think maybe this is more prevalent than I realized. Because it is something that people don't want to talk about". In short, while audience members' perception of their susceptibility to suicide did not noticeably increase after seeing a Let's Talk performance, their understanding of its prevalence and impact, and their willingness to talk openly about the topic increased.

Some believed that depression and suicidal thoughts lay just beneath the surface of our everyday interactions. For instance, Abby said, "You know, I could, you know any one of us could go home and just decide that, all of a sudden, you know, we're sick of the facade or whatever". Reference was made to the play as having triggered awareness of the facades people wear: "Well, it did make me realize, like she said, the masks that people have. You can't assume that people are feeling or you know acting or you know a certain way, because you don't know what's under the surface".

Boys, on the other hand, tended to focus on individual level experiences, be less open about suffering and deny vulnerabilities (Tables 3,4,5). 
Table 5. Barriers to help-seeking subcategories by gender.

\begin{tabular}{lccc}
\hline Barriers to help-seeking & Frequency in category N (\%, subcategory) & Frequency for females N (\%, transcript) & Frequency for males N (\%, transcript) \\
\hline Defensive avoidance & $25(43)$ & $5(1)$ & $20(4)$ \\
Lack of resources & $6(10)$ & $6(1)$ & - \\
Stigma against treatment & $1(2)$ & - & $1(0)$ \\
Lack of awareness & $7(12)$ & - & - \\
Fear of being shunned & $2(3)$ & - & $2(0)$ \\
Experience of being shunned & $6(10)$ & $1(0)$ & $6(1)$ \\
Denial & $5(9)$ & - & $3(1)$ \\
Lack social support & $3(5)$ & & $3(1)$ \\
Stigma about mental illness & $3(5)$ & $452(100)$ & \\
Total & $58(100)$ & &
\end{tabular}

The most noteworthy quote came from a Native American boy, Eric, age 17, who did not speak too often. He was calm and reserved in the way he spoke of his father's alcohol and drug abuse as well as physical abuse. He mentioned them all casually and then explained how he remains to peaceful throughout daily life, when he said:

But my grandpa, he would tell me when I would have problems with my dad or my mom sometimes, he would tell me: if you're depressed, you're living in the past; if you're anxious, you're living in the future; but if you're at peace, you're living in the present. So ever since I was six years old, I would always sit and tell that to myself. I was always the chill kid. Chill and happy never really depressed. Always chill and laid back. I don't really think about suicide. There's not enough time for that.

Another young man, Honor, 16, shared his suicide experience, but did not mention it as an experience that is shared by others: "Last summer, I tried to commit suicide. I took 29 oxycodone, 28 mood stabilizers, and 10 melatonin. Then I went to the hospital and my heart rate was 5's, in the single digits".

One boy, 17, described his feelings of being alone in the world. He expressed feelings of being isolated from his family, and an absence of anyone with whom he felt comfortable sharing their emotions. "When you're that young and you feel estranged from your family, (getting professional help is) detrimental. There's nothing there, there's no hope for me left in the world. Nobody wants to talk about that".

Most telling were the gender difference in response to a question about barriers to help-seeking, asked during the focus groups and individual interviews with the participants in the first town to host the theater performance. Both males and females identified stigma associated with the experience of mental health problems as a barrier to accessing help but boys were twice as likely to express concern about their friends and, especially, their parents knowing about their psychological distress (Table 5). In one group, not a single girl mentioned parents as a barrier, while 4 of the 6 boys indicated that they would not want their parents to know if they were struggling because they would respond negatively. In individual interviews, 13 out of the 22 total boys said that they would be "uncomfortable" with their parents knowing about their struggles. As one put it; "not trying to put parents in a bad way or anything but they can kind of be harsh, like 'you just need to man up and quit feeling sorry for yourself". Boys were far more likely than girls to express concern about being judged for experiencing mental health problems. Eight boys and no girls expressed fear or experience of being shunned as a reason to avoid seeking help. Twenty boys and only five girls expressed defensive or avoidant response regarding seeking professional help (Table 5).

\subsection{Attitudes toward personal disclosure}

As might well be expected, given gendered norms surrounding personal disclosure, girls tended to advocate sharing, whether to a mental health professional or to peers; "Just talking to a friend can make it...not everything feel better but it can make it, it can make it feel better". They also talked about expressing feelings through art and music (Table 3).

Overall, girls were more likely to suggest activities as an outlet for the expression of feelings; as a way not to keep them bottled up. For example, one audience member suggested bringing the play to workplaces to shift the culture towards disclosure and open discussion:

Because, so, I'm at the other hospital and I like the idea of bringing a play to that group, because it's almost assumed that they would know how to deal with it, because they know about this kind of thing - they're in the medical field. Obviously they're not and I bet if the same thing happened at - on our intensive care unit it could be very similar. That there wasn't much talk about it. So, maybe outside of an incident, just having some sort of performance could be just really beneficial to that... community (Elizabeth, 23).

Boys, on the other hand, discussed the pressure not to talk about personal problems, to joke or make light of the issue or to simply not talk at all; "They try to be tough and be like, 'I'm not depressed, I don't need help". While several boys acknowlegded the importance of talking about one's feelings, they were unanimous in identifying the so- 
Table 6. Beliefs about effective coping strategies.

\begin{tabular}{|c|c|c|}
\hline & Males & Females \\
\hline \multirow{5}{*}{$\begin{array}{l}\text { In response to the question, } \\
\text { "What do you think teens } \\
\text { can do to help themselves } \\
\text { feel better if they are feel- } \\
\text { ing down or depressed?" }\end{array}$} & $\begin{array}{l}\text { "Find something to do to take your } \\
\text { mind off of it." }\end{array}$ & "Find someone, like a friend or family member, to talk to" \\
\hline & $\begin{array}{l}\text { Try a new thing, like sports or new } \\
\text { activities }\end{array}$ & Write about it/journaling/poetry \\
\hline & Get outdoors & Join a group \\
\hline & Listen to/play music & $\begin{array}{l}\text { "I think people are uncomfortable living affirmation and they're uncom- } \\
\text { fortable receiving it. I think it's like anything else, we really need to just } \\
\text { practice it. You know, take those steps forward and even if it's uncom- } \\
\text { fortable, just practice it. And I think it produces joy when we do." }\end{array}$ \\
\hline & $\begin{array}{l}\text { "And a part of that is because grow- } \\
\text { ing up on the rez, you're, it's, it's } \\
\text { hard. It may seem difficult and, so } \\
\text { you've actually lived there. You } \\
\text { know that it takes skills to survive } \\
\text { on the rez." }\end{array}$ & $\begin{array}{l}\text { "And so exactly what's happening here is when people de-stigmatize } \\
\text { the ability or the, the stigma of talking about suicide and talking about } \\
\text { depression and saying that it can be talked about, then it, it provides an } \\
\text { opportunity to allow the interventions to happen and to voices going to } \\
\text { be heard that says let's get people trained out there, let's get this out of } \\
\text { the dark alleys and into public dialogue that says we can talk about it, } \\
\text { and through that reduce the risk of that." }\end{array}$ \\
\hline
\end{tabular}

cial pressure not to open up or share personal feelings with others. As noted above, in alignment with stereotypical norms of masculinity, the participants identified stigma surrounding self-disclosure regarding emotional distress.

And its weird because suicide and depression are something that aren't brought to the forefront and a lot of people put on a face and definitely hide behind it. But the fact is, it's so common. I know I have certainly done with family and different family members who have dealt with depression and severe anxiety and stuff and like there is a lot of stuff going on with them (Hat, 16).

Indeed, male participants discussed the taboo around suicide as a barrier to helping their friends. One male actor, age 16, described how he and his friends had overlooked signs of trouble among thir peers: "I do agree with Macee and Kevin that its not a burden but I do feel bad because after dong this its like how much I've overlooked I guess is sad. Like now you can see the signs and you realize that to help someone they don't have to come and flatout say, 'I'm suicidal."' Boys also commonly talked about not knowing how to talk to their friends about their problems, in the instances where they mentioned wanting to reach out, whereas only five girls mentioned concerns about not knowing how to raise the issue with friends, among 18 who said they wanted to reach out to others (Tables 3,6).

Nonetheless, the male actors also shared how their participation in the play had helped them disclose vulnerable emotions that they had never been able to talk about previously:

I'm really susceptiable to putting up walls and not dealing with my emotion- just bottling them up until the override and I explode for like a week and a half. This entire experience has really gotten me to open up with people
I consider dear to me like my friends. So there's that aspect of it; I'm sure a lot of people also feel that way. Because of this experience, we ourselves learned to talk and to express things that we're feeling - whether they be good or upsetting, just different things and I think we can all grow from that. That's certainly what I've taken from this is that I need to be as open as our project has asked of us (Hat, 16).

\subsection{Beliefs about effective coping strategies}

While it was not a specific research question, in the course of the interviews and focus group discussions, another theme emerged in the data; views on the best ways to cope with mental health problems. Girls were more likely to cite emotional sharing, especially through connection with others and boys more likely to cite distraction activities, to avoid focusing on depressive symptoms.

In response to the question, "What do you think teens can do to help themselves feel better if they are feeling down or depressed", boys suggested things like spending time outdoors, participating in a sport or activity or otherwise "distracting yourself" from thinking about their problems. Girls' recommendations included talking to a friend or family member about their feelings, journaling and expressing feelings through poetry or joining a support group (see Table 6).

The girls' ideas about how to cope with psychological distress differed from the boys in two important ways: (1) girls recommended confronting/addressing problems while boys thought finding ways not to think about them was a better strategy and (2) girls were more likely than boys to advocate for connecting with others. Boys' suggestions were more individualized. 
Table 7. A priori coding categories, sub-categories and descriptive themes.

\begin{tabular}{|c|c|c|c|}
\hline Supra codes & Main codes & Sub categories & Examples \\
\hline \multirow{9}{*}{ Communal vs. individual suffering } & \multirow[t]{6}{*}{ Stigma } & Self-Stigma & Against sharing emotional vulnerability \\
\hline & & Public Stigma & Experience with stigma \\
\hline & & \multirow{4}{*}{ Stigma of Help-Seeking } & Defensive Avoidance \\
\hline & & & Lack of access to sources of support \\
\hline & & & Fear of being shunned \\
\hline & & & Stigma about mental illness \\
\hline & \multirow[t]{3}{*}{ Social Isolation } & Social Isolation & Feelings of Loneliness/Isolation \\
\hline & & & Disconnection from others \\
\hline & & Lack of Authenticity & Thwarted belongingness \\
\hline \multirow[t]{3}{*}{ Male vs. female differences } & \multirow[t]{3}{*}{ Factors of Suicide } & \multicolumn{2}{|l|}{ Social Isolation (Loneliness) } \\
\hline & & Perceived hurdensomeness & Perceive oneself as a burden \\
\hline & & Percerved ourdensomeness & $\begin{array}{l}\text { Belief that one's death would be worth more } \\
\text { than one's life }\end{array}$ \\
\hline \multirow{8}{*}{ Perceived efficacy } & & Negative family dynamics & \\
\hline & & Suicidal ideation & \\
\hline & & Survivor Responses & Confusion \\
\hline & & & Anger \\
\hline & & & Guilt \\
\hline & \multirow[t]{3}{*}{ Behavioral Intentions } & Behavioral Intentions & $\begin{array}{l}\text { To communicate with others about sui- } \\
\text { cide/depression }\end{array}$ \\
\hline & & & To engage with prevention resources \\
\hline & & & To access help \\
\hline \multirow{7}{*}{ Perceived threat } & \multirow[t]{7}{*}{ Self Reports of Mental Health issues } & Hopelessness & \\
\hline & & Self-harming & \\
\hline & & Isolation (loneliness) & \\
\hline & & Uncontrollable thoughts & \\
\hline & & Helplessness & \\
\hline & & Depression & \\
\hline & & Suicidal ideation & \\
\hline
\end{tabular}

Overall, despite the somewhat atypical sample of adolescent boys, the findings suggest that both boys and girls tend to conform to stereotypical gender roles in terms of their understandings about mental health and beliefs about coping with psychological distress. This finding underscores the importance of considering gendered norms of behavior in developing suicide prevention strategies and tailoring prevention messages by gender.

\section{Discussion}

The gender paradox of suicide exists around the world and means that, despite lower reported levels of psychological distress, boys and men die by suicide far more frequently than girls and women. Some countries, like Finland, have specifically addressed these gender gaps and have had some success reducing the male suicide rate. Finland has done this recently primarily through increased availability of mental health services and increasing psychosocial supports [2]. Others have implemented suicide prevention programs directed specifically at particular groups of men, such as active duty military and/or veterans, hunting clubs or maledominated occupations or have centered on challenging norms of dominant masculinity like stoicism and not burdening others with their personal problems. Though ostensibly applying to all men, the target of these campaigns seems to be adult men, with perhaps more rigid views of masculinity.

The rise in identity talk and open communication about transgender, gay, lesbian, queer and transexual identities in recent years has the potential to challenge the dominance of conventional understandings of masculinity but the evidence to date indicates that it has not resulted in a reduction in the power of heteronormative masculinity, nor the health risks associated with conformity to gender norms [33]. Despite the increasing acceptance of multiple sexual orientations, gender identities and gender expressions, few such orientations have reduced the binary nature of our current gender system and associated cultural norms. Indeed, discussions about the experience of transgender individuals often focus on "passing" as the sex category that aligns with the individual's gender identity. There 
is a dearth of research on how nonbinary individuals navigate gender role expectations and whether greater acceptance of nonbinary people will challenge the gender binary $[34,44]$. Hence, while suicidal risk factors do exist that are unique to GBLTQ identities, the need for uniquely tailored research and work to address such factors does not undermine the need for interventions and research to address the role of masculine (and feminine) stereotypes in contributing to suicide risk in U.S. society, and internationally. This could occur in tandem with research into the potential for the aceeptance of nonbinary identities to challenge cultural gender rorms.

By focusing on high school aged boys, this study adds to our understandings of how cultural norms of masculinity shape the experience of emotional distress, coping strategies and attitudes toward help-seeking. And by comparing the responses of boys with their female counterparts, we can begin to map gender differences in behaviors related to mental health and develop tailored interventions that are more effective. Three themes emerged from the data:

(1) Boys take a more passive role to helping others in distress than girls. Girls were more likely to say that it's important to reach out to others and ask if they need help. Boys more commonly said that they would be supportive if a friend or family member came to them for help.

(2) Girls are more likely than boys to disclose their personal problems to others. Boys, even in this arguably less hyper-masculine sample than the larger population, frequently cited pressure not to talk about their feelings or to appear to need help. Further, the girls were far more likely to talk about psychological distress as common or even "normal" for teens, while the boys focused on the individual sufferer.

(3) Boys expressed more reluctance to coping with depression or emotional distress by examining their feelings. While girls believed that talking about one's problems or journaling about them would help them feel better, boys more commonly talked about "taking their minds off" their problems by focusing on something else or distracting themselves with activities.

Because this study used qualitative data, the findings cannot be generalized to the larger population. However, they can serve as a guide for further research and the development of gender-specific prevention campaigns. While it is clear that suicide prevention programs for men need to continue to underscore the importance of talking about one's problems and not suffering in isolation, it is possible that they may need to address other barriers, such as a reluctance to examine one's own psychological distress and an unwillingness to reach out to others who they suspect might be struggling. Moreover, if further research confirms that boys and men are more likely than girls and women to perceive emotional distress as unusual or abnormal, then campaigns that underscore the prevalence of mental health problems may be crucial for men. If psychological suffer- ing is understood to be a common and normal part of the human experience, it may encourage more men to acknowledge their struggles and seek help in addressing them. Normalizing the experience of depression, anxiety and other mental health challenges has the potential to dismantle the stigma still associated with emotional suffering and asking for help.

However, given the pervasiveness of conventional gender norms in U.S. culture, particularly those associated with heteronormative masculinity, addressing the high rate of suicide among boys and men may require a larger effort to challenge understandings of manhood more generally. As Shakya et al. [43] conclude, "Gender transformative interventions that include educational and awarenessbuilding activities and that strengthen social support systems for adolescents hold significant potential for simultaneously changing gender norms and improving health, and they warrant further exploration" [33] (pp. 537). This means that future interventions intended to reduce suicide among boys and men will likely need to directly confront expectations of masculinity as a barrier to help-seeking behavior and model alternative ideals of manhood. Finland's success in reducing its suicide rate, especially among men, was the result of a multi-pronged national effort. Following a "psychological autopsy" of all 1397 suicides in the country in 1987, the country implemented training for health care professionals to assess psychological distress as part of routine health exams. This meant directly asking about suicide, including specific questions about suicidal ideation. Finland also developed a nation-wide mental health care network to increase access to care and encourage help-seeking, partnered with private agencies to create prevention campaigns targeting men's groups and distributed a Suicide Prevention Toolkit for media professionals. Within a decade, Finland's suicide rate dropped by half, primarily among men [45].

\section{Conclusions}

The findings of this study suggest that techniques could include depictions or examples of a wide range of boys and young men intervening to help others, seeking companionship to cope with feelings of distress and exploring feelings as a coping strategy rather than avoiding thinking about problems. Taking such an approach also holds the potential to challenge heteronormative masculinity in the culture at large, with far-reaching implications for improving men's health.

\section{Author contributions}

All authors contributed to the study conception and design. Material preparation, data collection and analysis were performed by JCH, SNK and VM. The first draft of the manuscript was written by SNK and all authors commented on previous versions of the manuscript. All authors read and approved the final manuscript. 


\section{Ethics approval and consent to participate}

This work was approved by the Institutional Review Board at Montana State University Billings (Approval No. IRB00001622), and written informed consent for all participation in the research was obtained.

\section{Acknowledgment}

We thank the Montana Idea Network for Biomedical Research Excellence for support and funding.

\section{Funding}

This work was funded by Montana INBRE, a program funded by the National Institute of General Medical Sciences division of the National Institutes of Health under Award Number P20GM103474.

\section{Conflict of interest}

The authors declare no conflict of interest.

\section{Appendix}

See Table 7.

\section{References}

[1] U.S. Centers for Disease Control and Prevention. National Vital Statistics System, Mortality Data. Atlanta, CDC. 2019.

[2] Office of Statistics Finland (OSF). Causes of Death. Available at: http://www.stat.fi/til/ksyyt/index_en.html (Accessed: 25 August 2021).

[3] Salk RH, Hyde JS, Abramson LY. Gender differences in depression in representative national samples: Meta-analyses of diagnoses and symptoms. Psychological Bulletin. 2017; 143: 783822.

[4] Freeman A, Mergl R, Kohls E, Székely A, Gusmao R, Arensman $\mathrm{E}$, et al. A cross-national study on gender differences in suicide intent. BMC Psychiatry. 2017; 17: 234.

[5] Mäki N, Martikainen P. A register-based study on excess suicide mortality among unemployed men and women during different levels of unemployment in Finland. Journal of Epidemiology and Community Health. 2012; 66: 302-307.

[6] Canetto SS. Suicide. Men and Masculinities. 2017; 20: 49-70.

[7] Kyung-Sook W, SangSoo S, Sangjin S, Young-Jeon S. Marital status integration and suicide: a meta-analysis and metaregression. Social Science \& Medicine. 2018; 197: 116-126.

[8] Lloyd B, Blazely A, Phillips L. Stigma towards individuals who self harm: impact of gender and disclosure. Journal of Public Mental Health. 2018; 17: 184-194.

[9] Niederkrotenthaler T, Reidenberg DJ, Till B, Gould MS. Increasing Help-Seeking and Referrals for Individuals at Risk for Suicide by Decreasing Stigma. American Journal of Preventive Medicine. 2014; 47: S235-S243.

[10] Schomerus G, Evans-Lacko S, Rüsch N, Mojtabai R, Angermeyer MC, Thornicroft G. Collective levels of stigma and national suicide rates in 25 European countries. Epidemiology and Psychiatric Sciences. 2019; 24: 166-171.

[11] Sirey JA, Bruce ML, Alexopoulos GS, Perlick DA, Friedman SJ, Meyers BS. Stigma as a barrier to recovery: Perceived stigma and patient-rated severity of illness as predictors of antidepressant drug adherence. Psychiatric Services. 2001; 52: 16151620.

[12] Corrigan PW, Rafacz J, Rüsch N. Examining a progressive model of self-stigma and its impact on people with serious mental illness. Psychiatry Research. 2011; 189: 339-343.

[13] Link BG, Struening EL, Rahav M, Phelan JC, Nuttbrock L. On stigma and its consequences: evidence from a longitudinal study of men with dual diagnoses of mental illness and substance abuse. Journal of Health and Social Behavior. 1997; 38: 177190.

[14] Evans-Lacko S, Brohan E, Mojtabai R, Thornicroft G. Association between public views of mental illness and self-stigma among individuals with mental illness in 14 European countries. Psychological Medicine. 2012; 42: 1741-1752.

[15] Kieran D. 'It Changed me as a Man:' Reframing Military Masculinity in the Army's 'Shoulder to Shoulder' Suicide Prevention Campaign. Journal of War \& Culture Studies. 2021; 14: 306323.

[16] Partonen T. 2 Suicide prevention in Finland. Injury Prevention. 2016; 22: A1.

[17] Doran CM, Wittenhagen L, Heffernan E, Meurk C. The MATES Case Management Model: Presenting Problems and Referral Pathways for a Novel Peer-Led Approach to Addressing Suicide in the Construction Industry. International Journal of Environmental Research and Public Health. 2021; 18: 6740.

[18] Movember Foundation. Staying connected. Available at: https:// us.movember.com/mens-health/suicide-prevention (Accessed: 28 August 2021).

[19] Hamilton E, Klimes-Dougan B. Gender differences in suicide prevention responses: implications for adolescents based on an illustrative review of the literature. International Journal of Environmental Research and Public Health. 2015; 12: 2359-2372.

[20] Rickwood D, Deane FP, Wilson CJ, Ciarrochi J. Young people's help-seeking for mental health problems. Australian E-Journal for the Advancement of Mental Health. 2005; 4: 218-251.

[21] Gulliver A, Griffiths KM, Christensen H. Perceived barriers and facilitators to mental health help-seeking in young people: a systematic review. BMC Psychiatry. 2010; 10: 113.

[22] Miller-Day M, Hecht ML. Narrative means to preventative ends: a narrative engagement framework for designing prevention interventions. Health Communication. 2013; 28: 657-670.

[23] Langellier KM. Performing Narrative Medicine. Journal of Applied Communication Research. 2009; 37: 151-158.

[24] Mazza JJ, Reynolds WM. School-wide approaches to prevention of and intervention for depression and suicidal behaviors. Transforming School Mental Health Services. 2008: 213-241.

[25] Van Schalkwyk GJ. Collage Life Story Elicitation Technique: A Representational Technique for Scaffolding Autobiographical Memories. Qualitative Report. 2010; 15: 675-695.

[26] Miles M, Huberman AM, Saldana J. Qualitative Data Analysis: A Methods Sourcebook. 3rd edn. Sage Publications: Thousand Oaks, CA, USA. 2014.

[27] Witte K. Putting the fear back into fear appeals: the extended parallel process model. Communication Monographs. 1992; 59: 329-349.

[28] Strauss A, Corbin J. Basics of qualitative research techniques. Sage Publications: Thousand Oaks, CA, USA. 1998.

[29] Fairclough N. Analysing Discourse: Textual analysis for social research. Routledge: London, UK. 2003.

[30] DeCuir-Gunby JT, Marshall PL, McCulloch AW. Developing and Using a Codebook for the Analysis of Interview Data: an Example from a Professional Development Research Project. Field Methods. 2011; 23: 136-155.

[31] Wimmer RD, Dominick JR. Mass Media Research: An Introduction. 10th edn. Cengage Learning: New York, NY, USA. 2013.

[32] Hayes AF, Krippendorff K. Answering the Call for a Standard Reliability Measure for Coding Data. Communication Methods and Measures. 2007; 1: 77-89. 
[33] Wolcott H. Writing up Qualitative Research. 3rd edn. Sage Publications: Newbury Park, CA, USA. 2009.

[34] Keller S, McNeill V, Honea J, Paulson Miller L. A look at culture and stigma of suicide: textual analysis of community theatre performances. International Journal of Environmental Research and Public Health. 2019; 16: 352.

[35] Iemmi V, Bantjes J, Coast E, Channer K, Leone T, McDaid D, et al. Suicide and poverty in low-income and middle-income countries: a systematic review. The Lancet Psychiatry. 2016; 3: 774 783.

[36] Pitman A, Rantell K, Marston L, King M, Osborn D. Perceived stigma of sudden bereavement as a risk factor for suicidal thoughts and suicide attempts: Analysis of British crosssectional survey data on 3387 young bereaved adults. International Journal of Environmental Research and Public Health. 2017; 14: 286.

[37] Park S, Lee Y. Factors that Affect Suicide Attempts of Adolescents in Multicultural Families in Korea. International Journal of Environmental Research and Public Health. 2016; 13: 1184.

[38] Pirkis J, Currier D, Butterworth P, Milner A, Kavanagh A, Tibble $\mathrm{H}$, et al. Socio-Economic Position and Suicidal Ideation in Men. International Journal of Environmental Research and Public Health. 2017; 14: 365.

[39] Lalonde CE. Counting the Costs of Failures of Personal and Cul- tural Continuity. Human Development. 2003; 46: 137-144.

[40] Chau K, Kabuth B, Chau N. Association between Suicide Ideation and Attempts and being an Immigrant among Adolescents, and the Role of Socioeconomic Factors and School, Behavior, and Health-Related Difficulties. International Journal of Environmental Research and Public Health. 2016; 13: 1070.

[41] Keller S, Austin CG, McNeill V. A theatre intervention to promote communication and disclosure of suicidal ideation. Journal of Applied Communication Research. 2017; 45: 294-312.

[42] Manzo K, Tiesman H, Stewart J, Hobbs GR, Knox SS. A comparison of risk factors associated with suicide ideation/attempts in American Indian and White youth in Montana. Archives of Suicide Research. 2015; 19: 89-102.

[43] Shakya HB, Domingue B, Nagata JM, Cislaghi B, Weber A, Darmstadt GL. Adolescent gender norms and adult health outcomes in the USA: a prospective cohort study. The Lancet Child \& Adolescent Health. 2019; 3: 529-538.

[44] Fiani CN, Han HJ. Navigating identity: Experiences of binary and non-binary transgender and gender non-conforming (TGNC) adults. International Journal of Transgenderism. 2019; 20: 181-194.

[45] Hakanen J, Upanne M. Evaluation Strategy for Finland's Suicide Prevention Project. Crisis. 1996; 17: 167-174. 